\title{
O processo de humanização e a busca pela qualidade na prestação de serviços em saúde: ações e desafios enfrentados por um grupo
}

\author{
Arlete Aparecida de Abreu. \\ Mestre em Administração pela Universidade Federal de Lavras- MG. Tutora do Curso de Administração \\ Pública à distância - UFLA. Email: arleteadm@yahoo.com.br
}

\section{Ricardo de Souza Sette}

Doutor em Administração pela Fundação Getulio Vargas - SP. Professor titular da Universidade Federal de Lavras - UFLA. Email: ricsouza@dae.ufla.br

RESUMO: Especialmente em um país como o Brasil, detentor de profundas desigualdades socioeconômicas, vários são os desafios na área de saúde. Um exemplo seria a ampliação do acesso aos serviços do setor, de maneira igualitária e com qualidade, além da co-responsabilização entre trabalhadores, gestores e usuários nos processos de gerir e cuidar. A PNH (Política Nacional de Humanização) está entre uma das tentativas de ação, por parte do governo, em busca de uma prestação de serviços em saúde mais humana. Desse modo, como essa política se infiltra no ambiente hospitalar, quais são suas ações e desafios? Entender como se dá a relação entre a busca da qualidade e a política de humanização, na visão de quem dela participa é necessário, a fim de se buscar novos cursos de ação que possam contribuir para a melhoria das ações em saúde e da prestação de serviços em si. A PNH não deve ser apenas um programa pontual, sendo necessário, portanto, que cada membro dentro das instituições prestadoras de serviços em saúde se torne mais consciente de seu papel junto à busca destes objetivos. Somente assim a qualidade e a equidade poderão ser uma realidade no campo da prestação de serviços em saúde.

PALAVRAS - CHAVE: Serviços ; Saúde ; Humanização ; Qualidade

\begin{abstract}
Especially in a country like Brazil, with many social and economic inequalities, there are several challenges in healthcare. An example is the expanding access to health services, beyond equal and quality actions, and the co-responsibility between workers, managers and users in the process of managing and health caring. The NPH (National Policy of Humanization) is one of the attempts of action improved by the government, seeking to provide human services in health. Thus, as this policy infiltrates the hospital environment, what are your actions and challenges? Understanding what is the relationship between the pursuit of quality and the humanization policy, in a participate 'view is necessary in order to search for new courses of action that may contribute to the improvement of health actions and services. The NPH should not be just a program point, is necessary that each institution's member witch providing health services to become more conscious of their role in the pursuit of these goals. Just in this way, the quality and equity can be a reality in the field of provision of health services.
\end{abstract}

KEY WORDS: Services; Health; Humanization; Quality 


\section{INTRODUÇÃO:}

O crescente aumento dos gastos em saúde pode ser explicado pelo envelhecimento da população brasileira, as doenças crônico-degenerativas, o aumento da violência e do stress, fatores que possuem suas raízes em condicionantes econômicos, sociais e culturais. Na busca do enfrentamento desses desafios, as políticas públicas tem tentado atuar nos diferentes níveis de atenção à saúde, envolvendo a população, a mídia e as unidades prestadoras de serviços como um todo.

Percebe-se que muitas dessas políticas são direcionadas à atenção básica em saúde, como o PACS (Programa de Agente Comunitário de Saúde), o PSF (Programas de Saúde da Família), a Farmácia Popular e o Programa Brasil Sorridente. São programas que atuam em busca da construção de uma cultura de prevenção, visto que o Brasil por muitos anos teve suas ações baseadas na medicina curativa, com ações que visavam somente à cura das enfermidades e não em ações que pudessem impedi - la de se desenvolver ou chegar a estágios avançados.

Essas políticas visam à redução dos gastos em saúde e o desenvolvimento de uma cultura preventiva, trabalhando na base, ou seja, nas comunidades, bem próximo a população que necessita de atenção, cuidado e informação. Contudo, as mesmas também se estendem em seus objetivos até alcançarem as instituições que prestam serviços em saúde. Um exemplo é a Política Nacional de Humanização que pode contribuir de maneira expressiva na busca de uma prestação de serviços que atenda aos três princípios doutrinários do Sistema Único de Saúde (a universalidade, a integralidade e a equidade), e que também auxilie na melhoria da qualidade, por meio de mudanças em processos e atitudes no ambiente hospitalar.

A PNH, portanto, se propõe a criação de novas relações no ambiente de trabalho, gerando uma dinâmica entre as equipes que nele se inserem, o que implica maior interação entre os gestores, membros e usuários. A política representa uma força que pode ser gerada e impulsionada fazendo com que os discursos referentes às práticas humanizadas andem em conjunto com estratégias para a melhoria da qualidade da prestação de serviços.

De acordo com o Documento Base para Gestores e Trabalhadores do SUS (2008), a humanização pode ser entendida pela valorização dos diferentes sujeitos implicados no processo de produção de saúde: usuários, trabalhadores e gestores, trabalhando em uma perspectiva multidimensional e em busca de vários objetivos. Por esta razão, o presente artigo tem como questionamento quais seriam as principais ações e os desafios enfrentados por um Grupo de Trabalho em Humanização (GTH) pertencente à um hospital localizado no Sul de Minas Gerais. Pretende-se identificar a destes membros sobre a política, sobre sua implantação e consecução em seu ambiente de trabalho, bem como delinear problemas enfrentados em sua prática.

\section{REFERENCIAL TEÓRICO}

\subsection{Prestação de serviços em saúde}

A Associação Americana de Marketing (AMA) define serviços como as atividades, vantagens ou mesmo satisfações que são oferecidas a venda ou que podem ainda ser proporcionadas em conexão com a venda de mercadorias. (LAS CASAS, 2006, p.17).

Os serviços apresentam natureza diferenciada em comparação aos produtos sendo relevantes quatro características principais: a intangibilidade (os serviços não podem ser tocados); a perecibilidade (os serviços não podem ser estocados); a inseparabilidade (os serviços são produzidos e consumidos ao mesmo tempo) e a variabilidade ou heterogeneidade (os serviços possuem alta variabilidade em seu desempenho). (GRONROOS, 1990).

Gronroos (1995, apud Neto, 2000, p. 3) afirma que a gestão de serviços é diretamente relacionada aos processos gerenciais, onde as estruturas vigentes são de menor importância. Assim o autor identifica seis princípios para uma gestão de serviços: (1) A equação do lucro e a lógica comercial: ou seja, a eficiência interna, objetivando o lucro, é inevitável, mas não pode ser primordial. Essa eficiência também deve ser direcionada tendo em vista a qualidade percebida pelo cliente no momento da prestação dos serviços. (2) Autoridade para a tomada de decisão: as decisões devem ser tomadas junto à linha de frente, devido às características inerentes aos serviços. Para isso, deve haver empowerment (potencialização) das equipes a fim de que elas sejam capacitadas com treinamento e autoconfiança, e possam lidar com a diversidade de situações existentes nos contatos com os clientes. (3) Foco Organizacional: a estrutura 
organizacional deve ser mais maleável, e os recursos devem dar suporte as atividades de contato com os clientes. (4) Foco de Supervisão: deve-se priorizar o encorajamento e suporte aos empregados. (5) Foco nas Avaliações: focar a satisfação do cliente em relação ao serviço recebido. (6) Sistemas de Recompensa: a produção da qualidade que deve ser percebida pelo cliente deve também ser foco dos sistemas de recompensa, sendo então diferentes do simples cumprimento de padrões predeterminados.

Assim, pode-se perceber a importância da gestão de serviços e como essa está diretamente relacionada à qualidade e excelência em sua prestação. É importante que sejam levados em consideração as especificidades do serviço em si, suas características próprias e também aquelas advindas do setor ou ramo em que se atua, a fim de uma gestão que potencialize os resultados satisfatórios, tanto economicamente quanto em relação à satisfação do cliente. Dessa maneira também são os serviços em saúde, onde o cliente tem papel fundamental sendo o agente responsável por informações que são relevantes em seu tratamento. Isso muitas vezes pode conferir a prestação de serviços um desenho totalmente diferente, facilitando os processos e agilizando a busca por essa qualidade.

De acordo com a OMS (Organização Mundial de Saúde), os sistemas de serviços de saúde podem ser definidos como o conjunto das atividades cujo propósito primário é promover, restaurar e manter a saúde de uma população. (World Health Organization, 2000).

Assim os serviços prestados em saúde devem atender a uma demanda social e ainda ser trabalhados como fonte de vantagem competitiva nas organizações que o prestam. As instituições em saúde se organizam e se estruturam de maneira a oferecer esse serviço a um menor custo e da melhor maneira possível.

\subsection{O nascimento do SUS e as Políticas Públicas em saúde}

De acordo com Fleury (1994, apud CONILL, 2002, p. 2) as mudanças ocorridas nas políticas de saúde após a Constituição de 1988, levaram a uma inclusão segmentada, ou seja, diversos "cidadãos" de diferentes "qualidades" cobertos por distintos benefícios. Isso demonstra bem como o poder público vem tentando, através das políticas públicas, a implementar todas as diretrizes do Sistema Único de Saúde (SUS).

Mendes (2002) coloca que há várias formas para a organização da prestação de serviços em saúde, mas, sobretudo elas agregam duas opções alternativas: os sistemas fragmentados ou os sistemas integrados de serviços de saúde. De acordo com o mesmo autor, os sistemas fragmentados são aqueles que se (dês) organizam através de um conjunto de pontos de atenção a saúde, isolados e incomunicados uns com os outros e assim por conseqüência são incapazes de prestar uma atenção continua aos cidadãos e de responsabilizar por determinada população. Já os sistemas integrados são os organizados através de uma rede integrada de pontos de atenção a saúde, prestando assistência continua a uma população definida - no tempo certo, no lugar certo, a qualidade certa e com um custo certo - e que, além disso, ainda se responsabiliza pelos resultados econômicos e sanitários relativos a essa população.

Isso também pode ser observado através das políticas de descentralização e municipalização, como o Programa de Saúde da Família (PSF) que trabalha a chamada Atenção Básica (AB) ou Atenção Primaria a Saúde (APS). De acordo com o Conselho Nacional de Secretários de Saúde (2007), nos países com sistemas de saúde universalizantes e includentes, como Europa, Canadá e Nova Zelândia, o termo APS está na pauta das políticas dos governos. Fazendo assim um contraponto a fragmentação dos sistemas de saúde, a superespecialização e ao uso abusivo de tecnologias médicas que determina necessidades questionáveis de consumo de serviços de saúde.

A história da saúde pública no Brasil se inicia com a vinda da família real portuguesa. Até então a saúde pública se limitava somente a recursos da terra, como plantas e ervas, e ao conhecimento empírico de curandeiros. Com a vinda da família real se criou a necessidade de uma estrutura sanitária mínima para que essa se instalasse na cidade do Rio de Janeiro.

De acordo com Salles (1971, apud POLIGNANO, 2008, p. 3), só existiam quatro médicos exercendo a profissão no Brasil Colônia e no Brasil Império, no Rio de Janeiro em 1789. Isso demonstra claramente como a saúde era negligenciada no Brasil no início de seu desenvolvimento como país. Com isso veio o aumento das epidemias e os navios começaram a querer não mais atracar no porto do Rio de Janeiro devido à situação sanitária da época. Isso afetou o país economicamente e só assim foi nomeado Oswaldo Cruz para cuidar do Departamento Federal de Saúde Pública.

Em 1920 Carlos Chagas, sucessor de Oswaldo Cruz, reestruturou o departamento e introduziu a propaganda e a educação sanitária como técnicas rotineiras de ação. 
Com a economia baseada na agricultura e conseqüente produção de café, aliadas a urbanização e chegada dos imigrantes, as péssimas condições de trabalho e a falta de direitos trabalhistas geraram greves em 1917 e em 1919. Assim em 1923 foi aprovada pelo Congresso Nacional a Lei Eloi Chaves que instituía a CAP'S (Caixas de Aposentadoria e Pensão). As CAP'S tinham como objetivo assegurar a saúde dos trabalhadores, porém isso era restrito somente a determinadas classes, como a CAP'S dos ferroviários, a primeira criada.

Em 1930, com a crise econômica, política e a conseqüente perda de poder por parte das oligarquias rurais, Getúlio Vargas entra em cena para em 1934 criar as Leis Trabalhistas através da CLT (Consolidação das Leis Trabalhistas).

Em 1960 há então a implantação do chamado INPS (Instituto Nacional de Previdência Social), que buscou unificar os benefícios e colocar todos os trabalhadores com carteira assinada como contribuintes o que gerou um aumento do volume de recursos capitalizados. Porém com esse aumento era impossível ao sistema médico previdenciário existente, atender a todos da população. Então o governo decidiu alocar os recursos na iniciativa privada, estabelecendo convênios e contratos. Assim em 1978 o INPS se tornou o INAMPS (Instituto Nacional de Assistência Médica e Previdência Social).

Já em 1985, com o fim do regime militar, com a eleição da Assembléia Constituinte em 1986 e a promulgação da nova Constituição em 1988, nasce no mesmo ano o SUS (Sistema Único de Saúde). Este procurava formular um modelo de saúde voltado às necessidades da população, procurando então resgatar o compromisso do estado para com o bem estar social, especialmente no que se refere à saúde coletiva. Mesmo nascendo em 1988, o SUS somente se consolida em 1990 com a Lei 8.080. Essa lei define o modelo operacional do SUS, definindo sua organização e funcionamento.

Sendo assim foram definidos princípios doutrinários e organizativos que sustentam as bases de funcionamento do SUS. Esses princípios são: a universalidade, a equidade e a integralidade. Já com relação ao funcionamento alguns princípios podem ser enumerados: a hierarquização, descentralização e participação popular.

Desse modo, as políticas públicas atuais lutam pelo cumprimento dessas diretrizes, na medida em que também buscam a prestação de serviços de maneira eficiente e efetiva. A PNH (Política Nacional de Humanização) vem no intuito de fazer com que a prestação de serviços em saúde se torne mais condicionada ao paciente como ser humano, como uma pessoa dotada de um contexto social, político, cultural, próprios dele. Dessa maneira então, pode contribuir com a melhoria da saúde em geral, e a crescente busca por ações inclusivas e determinantes de boas práticas em saúde.

\subsection{A humanização e a PNH (Política Nacional de Humanização)}

A PNH (Política Nacional de Humanização) foi instituída em 2003 pelo Ministério da Saúde, direcionada para pacientes do SUS (Serviço Único de Saúde), chamada então de Política Nacional de Humanização da Atenção e Gestão do SUS (HUMANIZASUS). Teve assim como objetivo, efetivar os princípios do

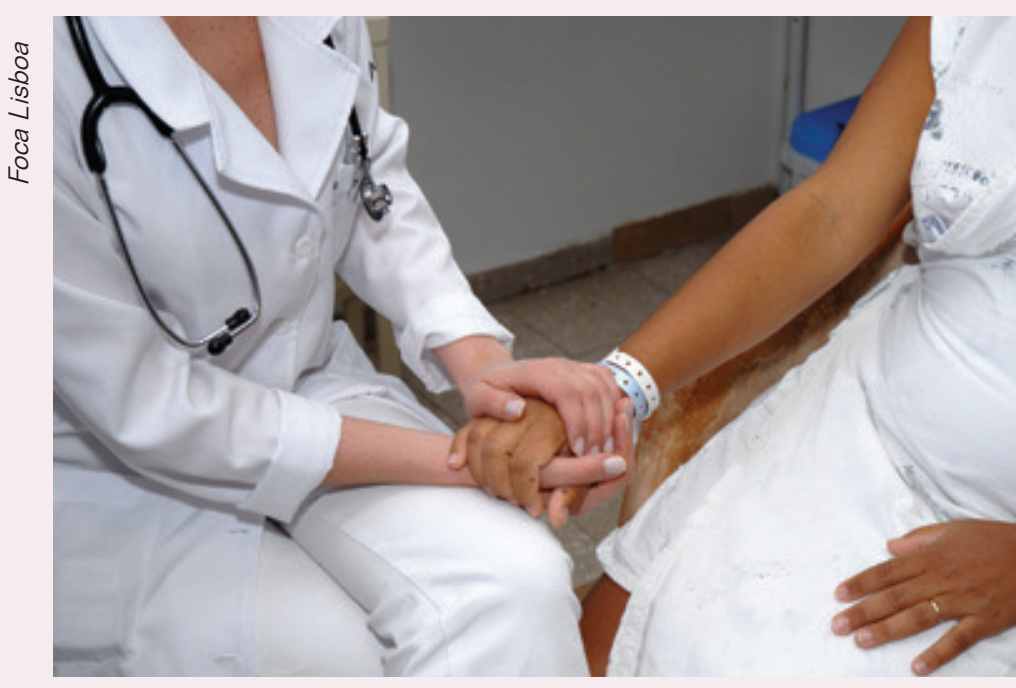

Sistema Unico de Saúde no cotidiano das práticas de atenção e gestão, bem como estimular trocas solidárias entre gestores, trabalhadores e usuários para a produção de saúde.

A Política de Humanização não deve ser vista como um programa, mas como uma política pública que atravessa/ transversaliza as diferentes ações e instâncias gestoras do SUS. Procura traduzir os princípios do SUS, construir trocas solidárias e comprometidas com a dupla tarefa de produção de saúde e produção de sujeitos, oferecendo um eixo articulador das práticas em saúde, destacando o aspecto subjetivo nelas presente. 
Essa política procura ainda, contagiar por ações e atitudes humanizadoras, valorizando os diferentes sujeitos implicados no processo de produção, fomentando a autonomia desses sujeitos e dos coletivos; aumento do grau de co-responsabilidade na produção de saúde e de sujeitos, estabelecendo vínculos solidários e de participação coletiva no processo de gestão, em defesa do SUS, que reconhece a diversidade do povo brasileiro e a todos tenta oferecer à mesma atenção a saúde, sem distinção de idade, raça, cor, origem, gênero ou orientação sexual. (HUMANIZASUS, 2008).

A Humanização do SUS ainda tem como objetivo uma mudança nos modelos de atenção e gestão, em sua indissociabiliade, tendo como foco as necessidades dos cidadãos, a produção de saúde e o próprio processo de trabalho em saúde. Valorizando então os trabalhadores e as relações sociais no trabalho, em busca de um SUS mais acolhedor, ágil e resolutivo, com processos mais articulados, melhorando as condições de trabalho e atendimento.

Desse modo, a humanização do SUS se operacionaliza através do resgate dos fundamentos básicos que norteiam as praticas de saúde no SUS, reconhecendo trabalhadores, gestores e usuários como sujeitos ativos e protagonistas das ações em saúde. A construção de espaços de encontro entre os sujeitos, a construção e troca de saberes; o trabalho em rede com equipes multiprofissionais com atuação transdisciplinar através do mapeamento, análise e atendimento de demandas e interesses dos diferentes sujeitos do campo de saúde, construindo redes solidárias, interativas, participativas e protagonistas dessa nova visão.

Contudo, essas ações e doutrinas podem ser adaptadas em um ambiente hospitalar, a fim de que elas atinjam não somente os usuários da rede SUS, mas os pacientes como um todo, de maneira que isso se torne parte de cada processo. Assim a Política Nacional de Humanização, pode ser considerada e manuseada como uma estratégia de gestão, a partir do momento em que atinge a todos os usuários e nessas condições corrobora para a melhoria da prestação de serviços como um todo.

\section{4 Qualidade na prestação de serviços}

A qualidade possui varias definições. O conceito de qualidade nos serviços de saúde vem mudando do enfoque técnico, para um enfoque mais abrangente, onde se tenta satisfazer os interesses, necessidades e demandas de três grupos: os prestadores de serviços de saúde, os que gerenciam tais serviços e os que os utilizam. Cada um desses grupos tem interesses e opiniões próprias sobre a melhoria dessa qualidade. (CAMILLERI; O' CALLAGHAN, 1998).

Camacho (1998, apud JÚNIOR E VIEIRA, 2002, p.2) observou que nas últimas décadas, em vários países, houve uma mobilização em torno da aplicação de programas de qualidade nas organizações hospitalares, com o objetivo de incrementar seu gerenciamento e melhorar a eficiência desses serviços.

Assim, diversas ações são feitas na busca da padronização e melhoria contínua e uma dessas ações é a busca pela Acreditação. De acordo com Feldman; Gatto e Cunha (2004) a Acreditação é um procedimento de avaliação dos recursos institucionais, voluntario, periódico, reservado e sigiloso que tende a garantir a qualidade da assistência através de padrões previamente aceitos.

Dessa maneira, tanto a esfera pública quanto a privada tem interesses em manter um sistema de serviços de saúde que possa garantir qualidade e desempenho significativo na melhora da saúde da população. A Acreditação vem nesse sentido, avaliar as instituições em saúde e conferir a estas um certificado que comprove que, dentro das regras técnicas, essas instituições estão aptas fisicamente, tecnologicamente e estruturalmente a prestar um serviço em saúde com qualidade.

Dessa maneira, de acordo com Cooperberg, M. R.; Birkmeyer, J. D.; Litwin, M. S. (2009) , o movimento pela melhoria dos cuidados de saúde enfrenta diversos desafios, metodológicos, clínicos, financeiros e políticos. Para o mesmo autor, porém, para que o movimento ganhe relevância e alcance de seu objetivo, é necessário que os médicos assumam papéis de liderança e aumentem os esforços para definir, medir, reportar e melhorar a qualidade no atendimento.

De acordo ainda com Debaig e Huete (1992, apud Araújo e Figueiredo, 2004) se uma organização quiser atingir a perfeição ou a qualidade total, o que tem que fazer é mudar a cultura, dotar-se de um sistema de valores e de um método ou programa que lhe permita praticar este conjunto de valores.

Dessa maneira não se pode encarar a busca pela qualidade como uma ação pontual. Muitos são os desafios enfrentados pelas instituições prestadoras de saúde e a busca dessa excelência exige varias outras mudanças que também não podem ser superficiais.

É preciso um envolvimento de toda a organização, e não somente os membros que estão diretamente ligados com a prestação do serviço em si. Os programas de avaliação da qualidade como a Acreditação 
estão aptos, prontos para a análise de aspectos estruturais, físicos e perceptíveis, o que deixa de lado as ações do dia a dia e a capacidade de cada membro dentro da estrutura como agente potencializador da qualidade e do bom atendimento.

É fato que a qualidade percebida pelo cliente se compõe de aspectos que são complexos e difíceis de se mensurar, e isso pode ser devido muitas vezes pela natureza também complexa dos serviços em saúde, porém as instituições devem sempre estar buscando essa melhoria contínua. Investir em seus processos, adequandoos a capacidade existente, trabalhando os colaboradores em seus anseios e particularidades, enfrentando os desafios impostos por restrições políticas, financeiras ou clinicas, na tentativa de adequar as políticas impostas pelo poder público, ao ambiente organizacional, criando assim meios, estratégias alternativas de ação.

Petitti e Derose (2003) afirmam que a distinção entre qualidade e mensuração do desempenho ainda não está clara na literatura. A medição do desempenho é um termo que pode ser usualmente aplicado quando a organização está sendo avaliada, quando o acesso, o custo e a eficiência são avaliados como componentes da qualidade. Já medidas de desempenho sob uma perspectiva de saúde da população são mais abrangentes, como indicadores de avaliação do pessoal de saúde, tendo como foco a interação individual entre médico e paciente.

Dessa maneira, alinhando a melhoria substancial que pode ser trazida pela busca da Acreditação, é necessário que as instituições em saúde repensem as políticas a que estão sujeitas como focos de mudança e renovação. Assim, fazendo com que a organização seja envolvida e levada a melhorias que sejam sentidas em todas as instancias, principalmente do ponto de vista do paciente e de sua patologia.

\section{METODOLOGIA}

Essa pesquisa se caracteriza quanto a seus fins como exploratória. Segundo Gil (1991), o estudo exploratório busca proporcionar maior familiaridade com o problema, com vistas a torná-lo mais explícito.

Já quanto aos meios essa pesquisa se enquadra no método estudo de casos. De acordo com Yin (2001), o estudo de caso é o modo de pesquisa empírica que investiga os fenômenos contemporâneos em seu ambiente real, quando os limites entre o fenômeno e o contexto não são claramente definidos.

Prezou-se pela não divulgação do nome do Hospital participante desta pesquisa, aqui chamado de hospital $X$, com o objetivo de resguardá-lo de qualquer informação que pudesse ser prejudicial. O objeto de estudo então é o grupo de humanização do hospital X, um hospital filantrópico, fundado em 09 de janeiro de 1941.

Situado na cidade de Lavras, no sul de Minas Gerais o hospital possui atualmente oitenta e oito leitos e dá suporte `a várias cidades circunvizinhas.

De acordo com Vergara (2005), os sujeitos de uma pesquisa são aqueles que fornecerão os dados que o pesquisador necessita para realizá-la. A coleta de dados então foi realizada através de entrevistas, aplicadas a doze pessoas sendo onze membros efetivos do grupo de humanização do hospital $\mathrm{X}$ e pertencentes a vários departamentos distintos: a gerente de hotelaria, a coordenadora da recepção e prontos socorros, a assistente social, a psicóloga, a gerente de marketing, a analista de qualidade, a gerente de recursos humanos, duas técnicas em segurança do trabalho, uma enfermeira, uma médica e por fim a superintendente administrativa. Além das entrevistas foi usada a observação participante a fim de se captar aspectos relevantes no grupo e em suas ações. Os depoimentos foram gravados e posteriormente transcritos.

As informações obtidas por meio das entrevistas foram tratadas pela técnica Análise de Conteúdo. Segundo Minayo (2007) a análise de conteúdo busca uma interpretação mais profunda do fenômeno, desvelando processos sociais ainda desconhecidos, referentes a grupos particulares, propiciando a construção de novas abordagens, revisão e criação de novos conceitos e categorias de investigação.

O objetivo das entrevistas foi o de descrever qual o entendimento do grupo sobre humanização e levantar os problemas e dificuldades enfrentadas por ele em seu curso de ação. Parte-se da perspectiva de que a humanização pode ser pensada como uma ferramenta que auxilie os gestores na busca da prestação de serviços em saúde com qualidade. Dessa maneira, foram feitos questionamentos direcionados ao significado da humanização; sua aplicação prática (os projetos considerados principais e seus efeitos); a repercussão destas ações sobre os funcionários do hospital; além de informações que pudessem identificar a posição de cada membro no grupo, suas funções, a comunicação entre os participantes e entre estes e a instituição como um todo, dentre outros pontos considerados importantes para o alcance dos objetivos explicitados neste artigo. 


\section{DISCUSSÃO}

O grupo de humanização do Hospital $X$ foi criado juntamente com a Política Nacional de Humanização, e também veio de encontro com algumas metas que o Hospital teria que cumprir fazendo parte de outra política chamada Pró - Hosp (Programa de Fortalecimento e Melhoria da Qualidade dos Hospitais do SUS em Minas Gerais). Política ditada pelo governo do stado de Minas e que visa à melhoria tendo como contrapartida pactos de gestão, através de um contrato de metas com a Secretaria Estadual de Saúde de Minas Gerais (SES/MG).

Percebe-se que o grupo de humanização do Hospital X, é um grupo heterogêneo que possui representantes de diversos setores, além de ser uma comissão aberta que aceita membros livremente. Possui o caráter burocrático de uma comissão, contendo livros-ata, documentos a serem arquivados, pastas com assunto do grupo e seu histórico, que são organizadas e manuseadas por uma secretária, que também é membro deste. Além disso, o grupo possui um caixa, onde contabiliza os recursos que consegue e aloca dentro do ambiente hospitalar e fora dele, ficando assim demonstrado o controle administrativo e a organização neste caso.

O grupo também possui uma coordenadora que é médica, e que tem um papel preponderante na tentativa de se fazer uma extensão dos princípios de humanização ao corpo clínico. Possui também uma vice-coordenadora, posto ocupado pela psicóloga do hospital e que também auxilia em momentos que há a exigência de contato com a diretoria, como em ações que exigem certa burocracia, como autorizações para liberação de recursos. Sendo assim, coordenadora e vice-coordenadora, são as responsáveis pelo elo entre o grupo e a diretoria administrativa do hospital, além da coordenadora ser o elo entre grupo e corpo clínico.

As reuniões do grupo são quinzenais e nelas o grupo discute democraticamente os problemas captados pelos membros. Assim, os membros discutem problemas que podem ser resolvidos e solucionados imediatamente e aqueles mais complexos são levados a diretoria ou alocados ao planejamento estratégico que o grupo possui. Os membros do grupo então captam a demanda dentro e fora do ambiente hospitalar e levam isso as reuniões para que a melhor solução seja encontrada.

As ações educativas do grupo são escassas, se limitando a exposições e explicações no treinamento de integração, que é o treinamento que os novos funcionários realizam ao serem admitidos no hospital. Existem outros, mas que podem ser considerados esporádicos, e visando pontos e problemas específicos e não a tentativa de se entender o que significa humanizar. Um exemplo seria a campanha antitabagismo que promoveu encontros entre médicos e enfermeiros, enfatizando a importância de se tentar abandonar o vicio. Um problema apontado para essa dificuldade, de se fazer treinamentos que tentem sensibilizar os funcionários e fazê-los conhecer a humanização, seria a alta rotatividade do hospital. Vários membros alegaram que o treinamento é como se fosse um tempo perdido, pois como o hospital possui atualmente 356 funcionários, e a rotatividade é alta, o período em que esses treinamentos teriam que ser refeitos (com funcionários novos) seria desgastante. Pensando então que os membros do grupo participam deste porque acreditam na humanização, mas tem outros assuntos próprios de seu setor que Ihes tomam muito tempo, esses treinamentos são inviáveis.

\subsection{Qual o significado da humanização para os membros do grupo?}

Quando questionados sobre o que acreditariam ser humanização, muitas foram as definições para o termo. As mais relevantes faziam referência a sentimentos considerados importantes para quem recebe o serviço e quem dele faz parte:

Entrevistado 12: "respeitar e tratar bem os colegas de trabalho";

Entrevistado 5: "ter afeto e carinho com o paciente";

Entrevistado 9: "trazer conforto ao paciente";

Entrevistado 7: "fazer do hospital um ambiente acolhedor, humano, resolutivo e ágil";

Entrevistado 4: "ato de amor ao próximo";

Entrevistado 6: "dar qualidade ao serviço prestado";

Entrevistado 2: "saber ouvir";

Entrevistado 8: "integrar corpo clínico e funcionários";

Entrevistado 11: "dar atenção ao paciente".

Assim o que se pode verificar é que todas as definições de humanização fazem menção ao próximo, sendo este o colega de trabalho ou o paciente. Além disso, pode-se perceber que vários membros fizeram menção a humanização como uma maneira de ter um atendimento, uma prestação de serviços com qualidade, ou seja, muitos membros do grupo associam a proposta da política à uma forma de melhorar os serviços prestados pela instituição.. 
Quando questionados sobre o que seria para eles a qualidade na prestação de serviços, as definições mais relevantes enfocavam sempre o outro (quem recebe o serviço prestado) ou o processo de execução do serviço em si, como pode ser verificado abaixo:

"percepção do serviço que você presta";

"uma escuta qualificada";

Entrevistado 7: "trazer resolutividade ao paciente"; "dar uma resposta ao paciente";

Entrevistado 9: "trabalho bem feito, com profissionalismo";

Entrevistado 6: "responsabilidade e respeito ao paciente";

Entrevistado 12: "fazer o melhor com o que se tem";

Entrevistado5: "tudo bem feito";

Entrevistado 4: "serviço com garantias";

Entrevistado 1: "desenvolver bem as competências técnicas e emocionais"; Entrevistdo 8: "bem estar do funcionário";

Entrevistado 2: "prestar uma assistência toda completa";

Entrevistada 11: "colaboração da equipe";

Entrevistado 3: "atenção e respeito aos funcionários"; "atenção aos pacientes".

O que se pode verificar com as declarações foi que cada membro, de cada área tem uma definição de qualidade, que é inerente as funções desenvolvidas pelo mesmo dentro do ambiente hospitalar, como por exemplo, para a assistente social (Entrevistada 7):

\begin{abstract}
"o atendimento com qualidade é uma escuta de qualidade, uma resolutividade do paciente, às vezes o paciente vem aqui... o que é esse atendimento de qualidade né? É dar uma resposta para o paciente, ou para o paciente ou para o próprio acompanhante dele né? Dar uma resposta que seja positiva ou negativa, fazer o encaminhamento né, para o próprio paciente ou acompanhante encontrar a solução do seu problema".
\end{abstract}

Ou como pode ser também pela coordenadora da recepção (Entrevistada 1):

"Qualidade também é uma questão muito ampla, eu acho que qualidade é você desenvolver bem as suas competências técnicas e emocionais. Você consegue alinhar as duas né, e administrativamente prestar um trabalho pautado em normas e também ter um excelente controle emocional, você é um profissional completo e vai atuar certamente com muita qualidade."

Ou ainda como uma das técnicas em segurança (Entrevistada 4):

"Ah um serviço de qualidade é como vamos dizer um serviço com garantias, sendo que aqui eu sei o que ta acontecendo, que eu vou ter um serviço de segurança entendeu? Acho que é um serviço que vai me assim deixar alguma segurança naquilo que eu to precisando".

Quando questionados sobre como o processo de humanização pode auxiliar a busca pela qualidade na prestação de serviços, os entrevistados concordam que há a necessidade de trabalhar os valores da humanização com os funcionários. Assim pretende-se que eles consigam preencher sua rotina com essas ações e o serviço seja prestado de maneira efetiva tanto tecnicamente quanto de forma humanizada.

Pode-se perceber também que cada membro consegue auxiliar o trabalho do grupo e discutir questões que fazem parte do seu dia a dia, do seu contexto. Além disso, quando as questões são discutidas e as ações propostas, cada membro fica responsável por uma ação, levando-se em consideração a afinidade do membro com o assunto, se foi o mesmo que encabeçou a idéia ou proposta e se possui tempo disponível para executar as atividades.

Quando questionados pela ação ou projeto do grupo que para eles teria sido importante e teria surtido o efeito desejado, os mais citados foram: o Projeto "Se liga" que buscava educar os funcionários e acompanhantes de pacientes sobre a importância do silêncio no hospital, mantendo um ambiente agradável e harmonioso. Outro citado foi a festa junina, onde foi oferecido um café especial aos funcionários, as comemorações do natal, dias das crianças e das mães. Outra ação importante é o bazar organizado todo fim de ano, que conta com doações de roupas que são vendidas aos funcionários por um preço simbólico, ajudando aqueles colaboradores que passam por dificuldades financeiras. O recurso arrecadado volta ao 
hospital através da compra de outros materiais como fraldas, para outros setores do hospital que atendem pessoas carentes.

As ações do grupo trazem benefícios que podem ser percebidos tanto por funcionários quanto por pacientes, como por exemplo, através de grupos religiosos que freqüentam o hospital levando mensagens de paz e aconchego.

As dificuldades e problemas destacados pelos entrevistados são: sobrecarga de trabalho que impede que os membros se dediquem mais ao grupo; falta de recursos, principalmente financeiros; falta de envolvimento do hospital como um todo, a falta de membros, de participação, principalmente de setores decisivos e que poderiam auxiliar muito na resolução de conflitos. Dificuldades em atingir os funcionários na tentativa de transmitir as idéias e valores do grupo e da humanização, também são colocadas nas entrevistas. Esta dificuldade pode ser resultado da alta rotatividade, já mencionada, ou por fatores culturais, como funcionários mais antigos e ortodoxos. Isso também ocorre com relação à equipe médica, em alguns casos. De maneira geral, o grande desafio é mudar o sentido da humanização dentro do hospital, porque de acordo com alguns entrevistados, o termo está se banalizando, perdendo a importância que deveria ter. É preciso sensibilizar e despertar os funcionários para a importância do grupo e da humanização com um todo.

\section{CONSIDERAÇÕES FINAIS:}

Como se pode verificar nesse estudo, o grupo de humanização enfrenta vários desafios em suas ações dentro do Hospital X, porém consegue contribuir de maneira significativa em muitos aspectos. Pode-se considerar que o grupo tem em sua essência, os seguintes papéis: é mediador de conflitos; facilitador de ações e demandas; canal direto entre diretoria e funcionário; sensibilizador das dores humanas; democratizador das necessidades e desejos; funciona como ouvidoria; aproxima os funcionários da realidade e tem a capacidade de desenvolver a empatia, dentre outros.

Assim, o grupo, dentro das ações estabelecidas pela Política Nacional de Humanização, pode ser gerenciado de maneira que contribua efetivamente e seja ferramenta imprescindível na melhoria do atendimento e da prestação de serviços. Para isso muitas barreiras como a cultura organizacional, a falta de interesse e de tempo hábil tem que ser contornados.

A busca de um maior envolvimento da instituição, desde a diretoria administrativa até os colaboradores mais próximos ao serviço prestado em si, é necessária. A conscientização tem que partir de cima e vir em forma de informação, com bons meios de comunicação atingindo as camadas hierárquicas subjacentes e se infiltrando em cada setor, sendo dele parte e regra. Somente assim, a idéia e os valores do grupo e da humanização conseguirão atingir efetivamente os membros da organização e poderão então contribuir de maneira relevante para a prestação de serviços em saúde.

Nesse aspecto, o Hospital X vem se transformando e se revendo. Na busca pela Acreditação e consequente melhora em seus processos, o grupo de humanização, a gerência de marketing e planejamento, trabalhando em associação com o departamento de qualidade e diretoria administrativa, estão buscando divulgar o Plano Diretor da instituição, com seu planejamento estratégico, tático e operacional para os próximos três anos. Nele, a humanização tem lugar de destaque, inclusive podendo ser mensurada através de indicadores de desenvolvimento e melhoria interna. Assim ações, como a disseminação dos valores, da missão e dos objetivos do hospital estão sendo propagadas pela instituição. Outra mudança é no slogan do hospital, que está sendo alterado na tentativa de representar todas essas novas concepções. Todas as ações em comunicação serão renovadas e manterão uma ligação direta com os princípios e valores do grupo.

Desse modo, não se pode dizer que os desafios e problemas deixam de existir, e sim que a instituição está agindo em busca da solução destes. Está buscando, associando ao desafio de humanizar, as mudanças técnicas, a comunicação e a estratégia, construindo novos caminhos, novas maneiras, se renovando, se redefinindo tanto interna quanto externamente. Pensar estrategicamente, com os recursos e possibilidades que se dispõe é essencial, significa adquirir vantagem competitiva. Saber alinhar o que é imposto pelo mercado e pelos órgãos reguladores ao objetivo da instituição de fato é vantagem gerencial. As instituições em saúde necessitam disso, dessa dinâmica que é subjacente ao setor, e por isso, devem ter em seus colaboradores o foco de cada mudança estratégica. Só dessa maneira, a Política Nacional de Humanização assim como outras políticas, deixará de ser apenas fatos e ações pontuais, para incrementar todo o contexto de saúde, envolvendo prestadores, colaboradores e usuários. 


\section{REFERENCIAS BIBLIOGRÁFICAS:}

ARAUJO, C. A. F.; FIGUEIREDO, K. F. Programas de Qualidade em serviços de saúde: um estudo dos programas implementados por três hospitais brasileiros. In: Encontro da Associação dos Programas de Pós Graduação em Administração, ENANPAD. Curitiba, 2004.

BENEVIDES, R.; PASSOS, E. A humanização como dimensão pública das políticas de saúde. Ciência e Saúde Coletiva, v.10, n. 3. Rio de Janeiro, 2005.

CAMILLERI, D.; O' CALLAGHAN, M. Comparing public and private hospital care service quality. International Journal of Health Care Quality Assurance, 1998.

CONILL, E. M. Políticas de atenção primária e reformas sanitárias: discutindo a avaliação a partir da análise do Programa Saúde da Família em Florianópolis, Santa Catarina, Brasil, 1994-2000. Cadernos de Saúde Pública. Rio de Janeiro, 2002.

COOPERBERG, M.R.; BIRKMEYER, J. D.; LITWIN, M. S. Defining high quality health care. Urologic Oncology: Seminars and Original Investigations, vol. 27. , 2009.

FELDMAN, L. B.; GATTO, M. A. F.; CUNHA, I. C. K. O. História da evolução da qualidade hospitalar: dos padrões a acreditação. Acta Paul Enferm. 2005

GIL, Antônio Carlos. Como elaborar projetos de pesquisa. São Paulo. Atlas. 1991

GRONROOS, Christian. Service Management and marketing: managing the moment of truth inn service competition. Lexington: Free Press, Lexington Books, 1990.

JUNIOR, G. D. G.; VIEIRA, M. M. F. Qualidade total e Administração hospitalar: explorando disjunções conceituais. Ciência e Saúde Coletiva, v.7, n.2. São Paulo, 2002.

LAS CASAS, A. L. Marketing de serviços. 4. Ed. São Paulo: Atlas, 2006.

MENDES, E.V. Serviços de saúde: o que os gestores deveriam saber sobre este sistema complexo. Fortaleza, Escola de Saúde Pública do Ceará, 2002.

MINAYO, M. C. S. O. O desafio do conhecimento: Pesquisa qualitativa em saúde. 10. Ed. São Paulo: Hucitec, 2007, $406 \mathrm{p}$.

MINISTÉRIO DA SAÚDE, SECRETARIA DE ATENÇÃO À SAÚDE, NÚCLEO TÉCNICO DA POLÍTICA NACIONAL DE HUMANIZAÇÃO. Humanizasus - cadernos de textos: cartilha da Política Nacional de Humanização. 4. ed., Brasília : Editora do Ministério da Saúde, 2008. Disponível em: $<$ http://bvsms.saude.gov.br/bvs/publicacoes/cartilhas_documento_base.pdf.> Acesso em 20 de junho de 2010.

MINISTÉRIO DA SAÚDE, SECRETARIA DE ATENÇÃO À SAÚDE, NÚCLEO TÉCNICO DA POLÍTICA NACIONAL DE HUMANIZAÇÃO. Documento base para gestores e trabalhadores do SUS. 4. ed. Brasília : Editora do Ministério da Saúde, 2008. Disponível em: <http://bvsms.saude.gov. $\mathrm{br} / \mathrm{bvs} /$ publicacoes/humanizasus_documento_gestores_trabalhadores_sus.pdf. > Acesso em 20 de junho de 2010.

NETO, J. C. Os serviços ao cliente como diferencial competitivo: implicações para a estrutura e gerencia das organizações. In : Encontro da Associação dos Programas de Pós Graduação em Administração, ENANPAD, Florianópolis, 2000.

PETITTI, D. B.; DEROSE, S. F. Measuring quality of care and performance from a population health care perspective. Annu. Rev. Public Health, 2003.

POLIGNANO, M. V. História das políticas de saúde no Brasil: uma pequena revisão. Cadernos do Internato Rural - Faculdade de Medicina/UFMG, 2001.

VERGARA Sylvia Constant. Métodos de pesquisa em administração. São Paulo: Atlas, 2005

YIN, Robert K. Estudo de caso: planejamento e métodos. 2. ed. Porto Alegre: Bookman, 2001.

WORLD HEALTH ORGANIZATION -The world health report, 2000. 